\title{
Normal median near nerve potential
}

W. Marques Jr. and A.A. Barreira
Departamento de Neurologia, Psiquiatria e Psicologia Médica, Faculdade de Medicina de Ribeirão Preto, Universidade de São Paulo, Ribeirão Preto, SP, Brasil

\author{
Correspondence \\ A.A. Barreira \\ Departamento de Neurologia, \\ Psiquiatria e Psicologia Médica \\ FMRP, USP \\ Av. Bandeirantes, 3900 \\ 14049-900 Ribeirão Preto, SP \\ Brasil \\ Fax: 55 (016) 633-1114 \\ Research supported in part by \\ CNPq and by FAEPA. Publication \\ supported by FAPESP.
}

Received October 11, 1996 Accepted October 7, 1997

\begin{abstract}
In routine studies of sensory nerve conduction, only fibers $\geq 7 \mu \mathrm{m}$ in diameter are analyzed. The late components which originate from thinner fibers are not detected. This explains why a normal sensory action potential (SAP) may be recorded in patients with peripheral neuropathies and sensory loss. In the present study we investigated the late component of the median SAP with a near nerve needle electrode technique in 14 normal volunteers ( 7 men and 7 women), aged $34.5 \pm$ 14.8 years. The stimulus consisted of rectangular pulses of $0.2-\mathrm{ms}$ duration at a frequency of $1 \mathrm{~Hz}$ with an intensity at least 6 times greater than the threshold value for the main component. Five hundred to 2000 sweep averagings were performed. The duration of analysis was 40 or $50 \mathrm{~ms}$ and the wave analysis frequency was $200(-6 \mathrm{~dB} / \mathrm{oct})$ to $3000 \mathrm{~Hz}(-12 \mathrm{~dB} /$ oct $)$. We used an apparatus with a two-channel amplifier system, $200 \mathrm{M} \Omega$ or more of entry impedance and a noise level of $0.7 \mu \mathrm{Vrms}$ or less. The main component mean amplitude, conduction velocity and latency and the late component mean amplitude, conduction velocity and latency were respectively (mean $\pm \mathrm{SD}$ ): $26.5 \pm 5.42 \mu \mathrm{V}, 56.8 \pm 5.42 \mathrm{~m} / \mathrm{s}, 3.01 \pm 0.31 \mathrm{~ms}, 0.12 \pm 0.04 \mu \mathrm{V}, 16.4$ $\pm 2.95 \mathrm{~m} / \mathrm{s}$ and $10.6 \pm 2.48 \mathrm{~ms}$. More sophisticated equipment has an internal noise of $0.6 \mu \mathrm{Vrms}$. These data demonstrate that the technique can now be employed to study thin fiber neuropathies, like in leprosy, using commercial electromyographs, even in non-academic practices.
\end{abstract}

\section{Introduction}

The compound sensory action potential (SAP) represents the time-space summation of the action potentials in each of the myelinic and amyelinic fibers comprising a nerve and is a measure of their function (1). Ideally, all the components constituting the SAP should be analyzed in clinical neurophysiology since different fiber populations may be selectively involved in peripheral neuropathies $(2,3)$. However, in routine studies of sensory nerve conduction, only fibers of 7 $\mu \mathrm{m}$ or more in diameter, that generate the main component of this potential, are analyzed. The late components, which originate
Key words

- Nerve conduction study

- Sensory conduction study

- Near nerve potential

- Nerve action potential

- Sensory action potential

- Median nerve

- Median nerve potential . Median nerve potential from $A \alpha$ fibers of smaller diameters, $A \delta$ and $\mathrm{C}$ fibers, are hidden in the noise (4); this explains why many patients with peripheral neuropathies and with clinical evidence of sensory involvement present a normal SAP $(3,5)$.

In 1966, Buchthal and Rosenfalck (6) developed a method to record potentials from fibers as small as 3 to $4 \mu \mathrm{m}$ in diameter. The main feature of this method is the improvement of the signal-to-noise ratio $(5,6)$, achieved by 1) the use of needle electrodes $0.7 \mathrm{~mm}$ in diameter, insulated up to $3 \mathrm{~mm}$ (active electrode) or $5 \mathrm{~mm}$ (reference electrode) from the tip; 2) reducing the impedance of the electrodes by passing an alter- 
Figure 1 - A near nerve recording from volunteer 5 . The arrowhead shows the late component. The main component is not visible because of the high gain. The number of averagings is 400,800 and 1200 from upper trace. nating current; 3 ) positioning the needle electrodes close to the nerve; 4) using a frequency band analysis of 200 to $4000 \mathrm{~Hz}$; 5) using an analysis duration of 40 or $50 \mathrm{~ms} ; 6$ ) employing an apparatus with an internal noise of $0.6 \mu \mathrm{Vrms}$ or less; 7) using a stimulus intensity sufficient to stimulate the finest fibers, and 8) making a large number of sweep averages.

The objective of the present study was to investigate the late component of the median SAP in normal volunteers. Certain modifications were required to facilitate recording with our equipment, and we evaluated the effect of these alterations on the data.

\section{Material and Methods}

Recordings were obtained from 14 median nerves of 14 normal volunteers ( 7 men and 7 women; mean age ( \pm SD), $34.5 \pm 14.8$ years; range, 18-64 years) who gave informed consent to participate in the study. The protocol was approved by the Hospital Ethics Committee. The neurophysiological examination was preceded by a screening questionnaire regarding peripheral neuropathies, particularly those more frequent in our city and region (alcoholic, nutritional, diabetic and inflammatory) (7), neurological examination and blood glucose analysis.

Stimulation was performed with ring electrodes previously immersed in saline solu-

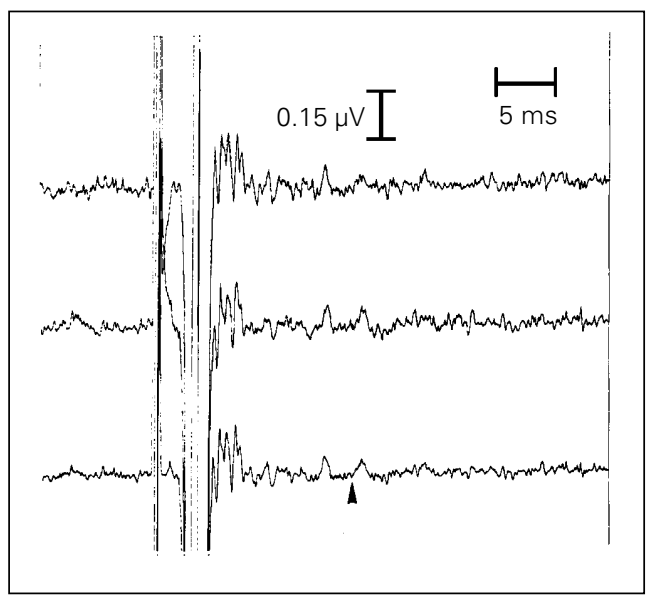

tion. The cathode was positioned proximally on the distal region of the middle phalanx of the third finger, and the anode on the distal phalanx of the same finger about $2 \mathrm{~cm}$ from the negative electrode. The stimulus consisted of 0.2-ms rectangular pulses at a frequency of $1 \mathrm{~Hz}$. Intensity was at least 6 times higher than the threshold value required to record the main component of the median nerve SAP. The maximum intensity of stimulation was limited by the sensation of pain reported by the subject.

Recordings were made using Dantec model 13L60 and 13L61 needle electrodes. Immediately before insertion, the recording electrodes were subjected to alternating currents $\left(10 \mathrm{~mA} / \mathrm{mm}^{2}\right)$ for $30 \mathrm{~s}$. The insertion site of the needle electrode was established by subliminal stimulation: a line rostral to the proximal fold of the wrist was traced and stimulated point by point until the subject defined the site at which a submaximal current of constant intensity triggered the strongest response. This site was noted and the same procedure was applied to record the compound muscle action potential of the abductor pollicis brevis muscle. The reference electrode was positioned 3 to $4 \mathrm{~cm}$ medially to the active electrode so as to provide a unipolar recording method. For optimization of the final position of the active electrode near the nerve, this electrode was transformed into a cathode and, after recording the motor response in the thenar region, the position was adjusted until the motor threshold was between 0.5 and $1.0 \mathrm{~mA}$. The temperature was kept above $33^{\circ} \mathrm{C}$.

Five hundred to 2000 sweep averagings in two or three series were performed. The duration of analysis was 40 to $50 \mathrm{~ms}$ and the wave analysis frequency was 200 (-6 dB/oct) to $3000 \mathrm{~Hz}(-12 \mathrm{~dB} / \mathrm{oct})$. The latency and amplitude of the main component were measured with a sensitivity of 5 to $20 \mu \mathrm{V} / \mathrm{div}$. The late component was studied with a sensitivity of 5 $\mathrm{V} /$ div and the gain ranged from $0.31 \mu \mathrm{V}$ to $0.07 \mu \mathrm{V} /$ div. The latencies were measured from the stimulus artifact to the first positive 
deflection of the respective potential. The amplitudes were measured from the first positive peak to the negative peak.

Stimulation and recording were performed using a Nihon Koden ${ }^{\circledR}$ Neuropack MEB71AO/K electromyograph with a twochannel amplifier system, $200 \mathrm{M} \Omega$ or more of entry impedance and a noise level of 0.7 $\mu \mathrm{Vrms}$ or less ( 1 to $10 \mathrm{~Hz}$ ). The measuring device was equipped with an 8-bit x 2channel A/D converter and a measurement memory of 24 bits $x 512$ points $\times 2$ channels. To be accepted as a late component the potential should satisfy the following criteria $(2,5,8): 1)$ to be clearly distinct from the background noise; 2 ) to become sharper with an increased number of averagings; 3 ) averaging replication should reproduce the findings, and 4) the amplitude should be at least twice that of the baseline noise level. Recurrent potentials (8), defined as a potential of prolonged latency $(>26 \mathrm{~ms}$ ) not preceded by other temporally close biological potentials, were not considered. Recordings with significant stimulation artifacts, excessive background noise, or excessive baseline oscillation were excluded from analysis.

Since several components usually follow the main potential (Figure 1), the late component was defined as the last component visualized that satisfied the above criteria.

Data were analyzed statistically using a $t$ test to compare sample means, followed by the nonparametric Wilcoxon test for result correction. Since much of the data exhibited marked inequality of variance, they were also analyzed at the $80 \%$ limit of confidence level. The lower limit for the normal amplitude of the main component was stipulated as half the mean amplitude of the potentials for normal individuals (9).

\section{Results}

The results are presented below and in Table 1.

Amplitude of the main component. The mean amplitude was $26.5 \mu \mathrm{V}(\mathrm{SD}=5.42)$ with a median of 26.05. The lower normal limit was established as $13.25 \mu \mathrm{V}$.

Conduction velocity of the main component. The mean conduction velocity was $56.8 \mathrm{~m} / \mathrm{s}(\mathrm{SD}=5.42$ ) with a median of 56.5. The tolerance limit ranged from 49.2 to $64.0 \mathrm{~m} / \mathrm{s}$.

Latency of the main component. The mean latency was $3.01 \mathrm{~ms}(\mathrm{SD}=0.31$ ) with a median of 3.05 . The tolerance limit ranged from 2.5 to $3.7 \mathrm{~ms}$.

Amplitude of the late component. The mean amplitude was $0.12 \mu \mathrm{V}(\mathrm{SD}=0.04)$ and the median 0.11 , ranging from 0.07 to $0.2 \mu \mathrm{V}$

Conduction velocity of the late component. The mean conduction velocity was $16.4 \mathrm{~m} / \mathrm{s}$ (SD $=2.95$ ) with a median of 15.6 . The confidence interval ranged from 11.3 to $20.9 \mathrm{~m} / \mathrm{s}$.

Latency of the late component. The mean latency was $10.6 \mathrm{~ms}(\mathrm{SD}=2.48$ ) with a median of 3.05. The tolerance limit ranged from 7.1 to $17.1 \mathrm{~ms}$.

Table 1 - Median near nerve sensory action potential in 14 normal volunteers.

AM, Amplitude $(\mu \mathrm{V})$ of the main component; $V M$, conduction velocity $(\mathrm{m} / \mathrm{s})$ of the main component; $L M$, latency $(\mathrm{ms})$ of the main component; $\mathrm{AL}$, amplitude $(\mu \mathrm{V})$ of the late component; $\mathrm{VL}$, conduction velocity $(\mathrm{m} / \mathrm{s})$ of the late component; LL, latency (ms) of the late component.

\begin{tabular}{ccccccccccccccc}
\hline & 1 & 2 & 3 & 4 & 5 & 6 & 7 & 8 & 9 & 10 & 11 & 12 & 13 & 14 \\
\hline AM & 26.4 & 14.7 & 15.2 & 25.7 & 40.2 & 35.3 & 17.5 & 23.0 & 36.6 & 27.8 & 27.6 & 17.7 & 41.0 & 22.4 \\
VM & 51.8 & 49.2 & 53.1 & 61.4 & 58.8 & 55.0 & 51.5 & 53.2 & 63.5 & 61.8 & 64.0 & 58.1 & 63.6 & 50.0 \\
LM & 2.8 & 3.7 & 2.8 & 2.9 & 3.3 & 3.0 & 3.3 & 3.1 & 2.6 & 2.8 & 2.5 & 3.1 & 2.8 & 3.1 \\
AL & 0.16 & 0.08 & 0.07 & 0.12 & 0.11 & 0.10 & 0.10 & 0.13 & 0.13 & 0.20 & 0.11 & 0.10 & 0.09 & 0.16 \\
VL & 15.6 & 19.5 & 15.6 & 16.5 & 11.3 & 14.5 & 14.9 & 20.6 & 19.6 & 14.0 & 13.7 & 14.0 & 20.9 & 18.2 \\
LL & 9.3 & 8.7 & 10.8 & 10.8 & 17.1 & 11.4 & 11.4 & 7.1 & 8.6 & 12.4 & 11.7 & 11.7 & 8.5 & 8.5
\end{tabular}




\section{Discussion}

According to Oh (10), the technique for recording the near nerve sensory action potential provides information that cannot be obtained with surface electrodes. This technique is fundamental when recordings obtained from electrodes positioned on the skin fail to demonstrate abnormalities in individuals clinically suspected to present peripheral neuropathy, or when there is insufficient discrimination to record the sensory potential. The technique can also contribute to studies of peripheral neuropathies.

The main SAP component represents the sum of potentials of sensory fibers larger than $7 \mu \mathrm{m}$ in diameter, and the main peak is a measure of the properties of fibers of more than $9 \mu \mathrm{m}$ in diameter (11). The biological factors that determine the amplitude are the number, or more precisely, the density of nerve fibers, their diameter and their relative conduction velocities (1). Latency and conduction velocity are determined by the fiber diameter and the characteristics of the myelin sheath (1).

Buchthal and Rosenfalck (12) reported normal conduction velocity values of $56.1 \pm$ $1.2 \mathrm{~m} / \mathrm{s}$ and $53.5 \pm 1.4 \mathrm{~m} / \mathrm{s}$ in subjects ranging in age from 18 to 21 and 40 to 60 years, respectively. Both of these velocities are close to the mean conduction velocity of $56.8 \mathrm{~m} / \mathrm{s}$ obtained in the present study. The mean amplitude of $26.5 \mu \mathrm{V}$ obtained in this study and that reported by the investigators cited above $(26.0 \mu \mathrm{V})$ were very similar.

Near nerve needle electrodes 0.6 to 0.7 $\mathrm{mm}$ in diameter, low noise amplifier and 500 to 2000 sweep averagings are required to detect the late SAP components (12). Under these conditions, a significant number of small fibers must be present for a $0.08-\mu \mathrm{V}$ potential to be distinguished from the background noise. In contrast, only 40 fibers of 7 $\mu \mathrm{m}$ are necessary to visualize the corresponding potential. This is because the amplitude of the potential is proportional to the sec- tional area of the fiber, so that a much larger number of small fibers are necessary to visualize a given potential compared to the number of larger fibers. Under normal conditions, the late component detected by the near nerve technique is determined by fibers of approximately $4 \mu \mathrm{m}$ in diameter according to Buchthal et al. (11), with an estimated conduction velocity of $15 \mathrm{~m} / \mathrm{s}$. This is similar to our own data $(16.4 \mathrm{~m} / \mathrm{s}, \mathrm{SD}=2.95)$ and to Buchthal et al.'s data $(16 \mathrm{~m} / \mathrm{s})(13)$ who analyzed the late component of 56 patients. These values differ from those of Tackmann and Minkenberg (4), who evaluated 37 nerves, reporting a value of $20.6 \mathrm{~m} / \mathrm{s}(\mathrm{SD}=$ 3.1). However, these investigators used a maximum of 1000 measurements and only studied potentials with an amplitude of 0.1 $\mu \mathrm{V}$ or more, parameters that exclude components of lower amplitude and velocity from analysis. As also reported by Buchthal et al. (11), potentials of less than $0.1 \mu \mathrm{V}$ were analyzed in the present study and more than 1000 sweep averagings were performed in some nerves to better define the potentials originating from small fibers.

Thus, our findings are similar to those reported in the literature, although the technique employed was not exactly the same. More sophisticated equipment has an internal noise of $0.6 \mu \mathrm{Vrms}$, while the apparatus used here has an internal noise of $0.7 \mu \mathrm{Vrms}$ $(1 \mathrm{to} 10 \mathrm{~Hz}$ ). Although this higher noise level may have rendered the examination more difficult by requiring a larger number of averagings, the detection and recording of late potentials were not affected.

The frequency analysis used in the present study was $200 \mathrm{~Hz}$ (-6 dB/oct) to $3000 \mathrm{~Hz}$ (-12 dB/oct). Buchthal and Rosenfalck (12) used 20 or 200 to $4000 \mathrm{~Hz}$ (3 dB) while Shefner et al. (5) used 200 to 4000 (3 dB). A high-pass filter (low frequency filter) is used to reduce the amplitude of the slow waves without attenuating the fast waves. The elevation from 20 to $200 \mathrm{~Hz}$ permits the attenuation of slow fluctuations without im- 
pairing the signals (2). According to Buchthal and Rosenfalck (12), the reduction in the low-pass filter (high frequency filter) from 5000 to $2000 \mathrm{~Hz}$ reduces the amplitude of a potential recorded on the wrist by only $15 \%$ and prolongs the passage from the positive to the negative phase by no more than 0.1 ms. Thus, when the amplitude of the potential is less than $2 \mu \mathrm{V}$ and there is no evidence for a fast component, the reduction in frequency is advantageous.

The number of sweep averagings appears to influence the last detected component significantly, although we have not specifically studied this aspect. Increasing this parameter causes smaller potentials with amplitudes as low as $0.08 \mu \mathrm{V}$ to become clearly distinct from the background noise. This is probably the best explanation for the fact that, while the conduction velocities of the last component detected by Shefner et al. (5) and that recorded here are similar, both are different from the value obtained by Tackmann and Minkenberg (4).

In conclusion, the present method proved to be technically reproducible and thus is applicable in the clinical evaluation of peripheral neuropathies, especially those that affect small fibers, such as leprosy. The modifications introduced to allow recording with commercial equipment did not significantly affect the results, although the examination may have become more time consuming and more uncomfortable for the patient. The number of sweep averagings should be large enough to permit the good definition of the late component.

\section{References}

1. Brown WF (1984). The Physiological and Technical Basis of Electromyography. Butterworth, Boston.

2. Ludin HP \& Tackmann W (1981). Sensory Neuropathy. Thieme Station Inc., New York.

3. McLeod JG, Hargrave JC, Walsh JC, Booth GC, Gye RS \& Barron AS (1975). Nerve conduction studies in leprosy. International Journal of Leprosy, 43: 21-31.

4. Tackmann W \& Minkenberg R (1977). Nerve conduction velocity of small components in human sensory fibers. European Neurology, 16: 270-279.

5. Shefner JM, Buchthal F \& Krarup C (1991). Slowly conducting myelinated fibers in peripheral neuropathy. Muscle and Nerve, 14: $534-542$
6. Buchthal F \& Rosenfalck A (1966). Evoked action potentials and conduction velocity in human sensory nerves. Brain Research, 3: 1-122.

7. Marques Jr W, Herrera RF, Trade ES \& Barreira AA (1992). Diagnóstico das neuropatias periféricas. Diagnósticos sindrômicos, topográficos e etiológicos. Arquivos de Neuropsiquiatria, 50: 448457.

8. Shefner JM, Buchthal F \& Krarup C (1992). Recurrent potentials in human peripheral sensory nerve: possible evidence of primary afferent depolarization of the spinal cord. Muscle and Nerve, 15: 1354-1363.

9. Kimura J (1989). Electrodiagnosis in Diseases of Nerve and Muscle. Principles and Practice. 2nd edn. FA Davies, Philadelphia.
10. Oh SJ (1993). Clinical Electromyography: Nerve Conduction Studies. 2nd edn. Williams \& Wilkins, Baltimore.

11. Buchthal F, Rosenfalck A \& Behse F (1984). Sensory potentials of normal and diseased nerves. In: Dyck PJ, Thomas PK, Lambert EH \& Bunge R (Editors), Peripheral Neuropathy. 2nd edn. WB Saunders Company, Philadelphia.

12. Buchthal F \& Rosenfalck A (1971). Sensory potentials in polyneuropathy. Brain, 94: 241-262.

13. Buchthal F, Rosenfalck A \& Trojaborg W (1974). Electrophysiological findings in entrapment of median nerve at wrist and elbow. Journal of Neurology, Neurosurgery and Psychiatry, 37: 340-346. 